\title{
Sciendo
}

\section{Student wellbeing during the pandemic: distance and continuing education}

\section{Darya Zamaraeva}

Peoples' Friendship University of Russia

email:zamya9666@,gmail.com

Julia Nikolashina

Peoples' Friendship University of Russia

email:nikolashinajuliaa@gmail.com

\section{DOI: $10.2478 /$ gssfj-2020-0015}

\begin{abstract}
It would be right to say 2020 took us by surprise. Currently, countries all over the world are faced with a pandemic and its consequences. People were not ready to change the type of education. Due to the constant presence of electronic smart devices at the screens during distance learning and due to the lack of social contacts, the mental and physical health of students does not change for the better. Students experience depression, anxiety, sleep disturbances, and distracted attention.

The idea of continuing education is reflected in the implementation of distance learning that received this name primarily due to its "flexibility" in terms of choosing the place, time, and sometimes the pace of learning. However, continuing education in the context of distance learning blurs the boundaries between personal time and work, which generally has a negative impact on mental bealth and learning effectiveness.

In most cases, the combination of continuing education and distance learning provokes an increase in the load on students.

However, both the educational structure and the student should be ready for distance learning. We are talking not only about the technical base, computer skills and individual programs, but also about the skills of independent work.
\end{abstract}

Key words: COVID-19, education, distance learning, phycology, continuing education, heuristic strategy

\section{Introduction}

Young people between the ages of 18 and 25 are at risk of developing a serious mental illness like bipolar disorder (Adams, Moore, 2007). Such diseases can be challenging to diagnose in the early stages. Students with severe mental illness find it more difficult to study and take exams. The prevalence of eating disorders is relatively high among students.

In some sense, students are more vulnerable than other categories of people. Adults who work and do actions in almost the same sequence from day to day do not have 
many new challenges. For example, adaptation to the educational process is most often a challenge for students. It takes much time at the university to study independently. Students need to understand in time how to prioritize their main work - learning. Such a comprehensive load can lead to mental disorders. As a result, this can cause poor academic performance. If we imagine a completely negative scenario, then the student's academic record may fall, which in the future may lead to expulsion. Among other things, it is more difficult for a person with mental disorders to reach their potential. Any failure can complicate a person's life, if not at this point, then in the future.

Students ` psychological deviations can manifest themselves in different forms. If we are talking about mild disorders, then it can be distress, growing anxiety. Subsequently, this can develop into more complex disease such as bipolar disorder (MacCabe et al., 2010). Any such deviation affects student productivity. This was the case before the pandemic began. With its appearance, everything became more complicated.

Educational institutions around the world have abandoned face-to-face classes and switched to interactive distance learning. Students have adapted to new educational processes. However, it was not easy for everyone.

Nobody knows how long the pandemic will last. Psychologists believe that the increase in the time spent at the computer and the lack of personal communication affect not only the mental but also the physical health of students. Not all students are comfortable with using a webcam, as it turns out that everyone is looking at the speaker's face in close-up. Therefore, everyone can see the student, but he can see nobody. This is disarming. The younger the responder, the more he or she thinks about his performance on camera. They are often shy and too self-critical.

Learning through calls via "MicrosoftTeams" or "Zoom" is a good option for today's fast-paced world. However, not everyone can switch to this method so quickly. Following one after another, lessons tire students due to the difficulty of identifying habitual non-verbal signals like body language, tone, facial expressions and voice. With the usual answer, students simply do not have time to press the microphone button in time and either an awkward silence is created, or it seems as if the teacher is talking to himself for some time. Students faced the problem of concentrating on the lessons. During the lecture, there is a great temptation to be distracted by social networks, pets or TV. Students are continually learning, and even though there are breaks, they find it increasingly difficult not to be distracted by less stressful activities. By continually switching to an extracurricular environment, students subconsciously want to reduce stress and anxiety levels.

According to psychologists, delays in video calls and other technical problems also make students more anxious. It turns out that the student cannot connect to the lesson, answer orally or hand over the homework due to circumstances beyond his control. Here the only thing left for students is to hope for understanding from the teachers. Unstable Wi-Fi connection crashes and other problems during the video session result in intermittent conversation and indistinctness. More empathetic individuals with social anxiety may be overly emotional inside and outside about these moments.

Students started to experience vision problems due to constant stress (Bernard et al., 2018). They spend a lot of time attending classes and doing homework. Moreover, 
they most likely also spend their free time in front of the screens of mobile devices to watch videos on "YouTube" or scrolling through social networks. Staring at one point for hours on end for a long time can lead to headaches (Nicolas, 2020), which also affect performance. The tasks are completed more slowly, which also affects the stress level.

Some students forgot to eat due to their complete immersion in their studies. The constant educational process dulls the feeling of hunger. Some students try to grab something quick and keep participating at the lessons. This increases the number of meals per day, which can affect the mood drop. Students in a different time zone may experience severe eating disorders.

However, thanks to distance learning, it has become easier for other students to eat healthy food at a certain time. In pre-coronavirus life, it was more difficult for people to combine healthy nutrition habits, not to overeat. They had to eat in a moment when the opportunity and time for this will appear.

The transition to an online education format negatively affected the sleep patterns of students, and their sleep became unhealthy (Brenda Prior, 2020). If the student is in the one-time zone and the teacher is in another, then the student's inner sleeping schedule is lost. The student does not see his plan of action, and this demotivates him. It can be difficult for him to wake up or, on the contrary, he may not sleep soundly, or he needs to stay awake until late at night.

Switch to distance learning provided a rare opportunity for students to study their psychological state and well-being outside the educational institution. From school for Public Health Research in the report called "Young People's Mental Health during the COVID-19 Pandemic" (McElroy et al., 2020) was found data of measuring a level of anxiety among students that is called the Pandemic Anxiety Scale (PAS).

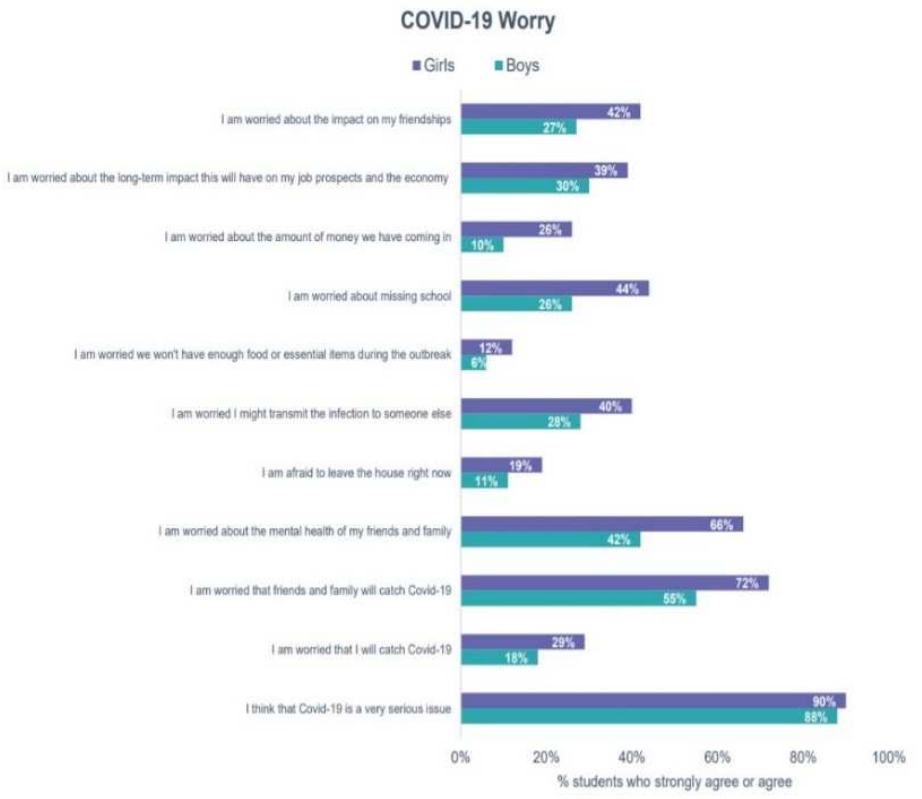

Figure 1 - COVID-19 Worry (source: NIHR School for Public Health Research) 
According to figure 1 , we see that $90 \%$ of girls and $88 \%$ of boys agreed that COVID19 was a serious challenge. The top two concerns for both boys and girls were 1) worry about their friends and family catching COVID-19 (72\% girls, 55\% boys) and 2) worry about the mental health of their friends and families ( $66 \%$ girls, $42 \%$ boys). In third place, we see a girl's concern about missing school (44\%), while boys worried about the long-term influence on their job and economic prospects $(30 \%)$. The general comparison shows that girls are worried more often (by 11 points) than boys.

Change in Percentage of Students at Risk of Anxiety

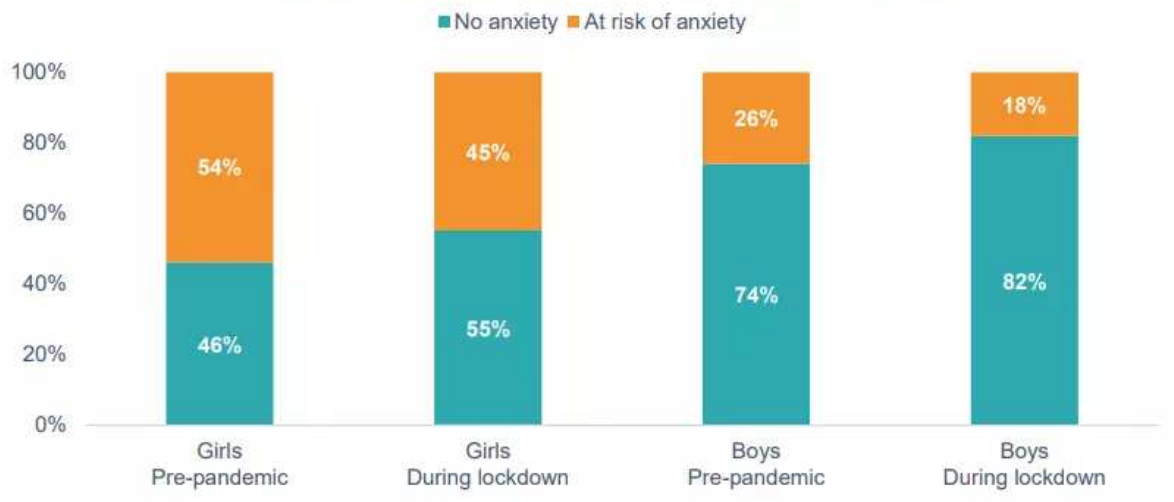

Figure 2 - Change in percentage of students at risk of anxiety (source: NIHR School for Public Health Research)

Based on these data, we can see that studying at home during isolation helped to avoid such moments as school bullying, communication with some peers and teachers. Some students felt somewhat closer to school as they did not attend and did not face the stress of a regular school.

In the actual realities, we miss the fact of social interactions and most often take it for granted. When we were walking between classes before the lesson or lecture starts, chatting with the people on the streets or small chitchatting with the teacher before class starts it all helped us by keeping our psychological state at the proper level. All these seemingly insignificant interactions influenced our lives. Without them, it will be difficult even for those individuals who do not like communication. Although teachers make every effort to create the same educational environment as it was in traditional teaching, many students find it difficult to learn the same way as it was before without interacting with other people. This becomes even more apparent when the student is accustomed to working in a team or in small groups. Lack of social interactions can lead to demotivation, anxiety, nervousness, and ultimately poor academic performance. Students often have to reflect on the new and unusual lifestyle. For a student, everything can deteriorate at times if he or she has already had negative experience about traditional education. If it was difficult for the person before, this does not mean at all that something will change. School or university are a natural environment for acquiring new knowledge. However, studying at home is much more difficult. Students are not motivated, and they feel overloaded. Some feel mentally exhausted from seemingly routine homework. 
The lack of a familiar curriculum and schedule makes distance learning especially difficult for students. The daily routine is very important for students because it makes an educational process a whole lot easier for them to solve the daily tasks that are assigned to them. When there is no clear schedule, students tend to be less interested in learning. It is easier for them to get distracted from the study without a clear vision of the situation.

Online education is a complex and time-consuming process that has advantages. Distance education can be called one of the safest ways to learn. People with mobility problems also have the opportunity to learn on an equal footing with others.

This skill helps to balance academic, professional and personal life. Time management empowers students to be more productive and efficient in managing their time. If they miss this moment, there is a chance of falling behind in the curriculum, which can lead to stress. Time allocation allows rethinking on how to use the time for optimal results.

\section{The situation in Russia with COVID-19 and education}

Russian universities are faced with a pandemic that no one was prepared. Educational institutions had to work hard to cope with the so-called coronavirus test. Members of the higher education system have managed to cope with the workload of pandemic during the coronavirus. However, the pandemic revealed the inflexibility and, in some respects, the low-tech nature of the educational process in universities. The existing capacities of universities are not enough for an effective and convenient distance-learning format for students and teachers.

A special analytical report "Stress test lessons. Universities in a pandemic and after it", developed on the initiative of the Ministry of Education and Science. It presents the expert opinion of university rectors on the work of the higher education system during a pandemic and the lessons or tasks that universities must solve. The rectors analyzed how distance learning affected students, teachers, whether the existing university infrastructure and management system of higher education coped with the load.

In its preparation, the results of previously published studies by the Higher School of Economics, the RANEPA Institute, the Agency for Strategic Initiatives (ASI) and others were used.

With the transition to distance learning in the second half of March, students were not sufficiently informed about the new requirements. The other half "just got lost" - in $15 \%$ of universities, there was no system of electronic communication with students. The authors of the report note that the majority of universities have also not implemented effective programs of psychological assistance to students. Social issues have also become aggravated. For example, the return of a significant number of students homes required financial assistance to buy tickets.

Another serious problem, according to the authors of the report, is the massive loss of jobs by students - $40 \%$ of students have decreased income.

In this case, the following actions could help students:

- it is necessary to correct social and economic differences among students by supporting employment;

$\circ$ introduce a cheap educational loan; 
○ to work out the option of continuing education for international students who have left Russia. The chances of such students to return to the normal educational process in the near future are "not obvious".

If at the beginning of work in the new conditions of the pandemic, one of the difficulties was the insufficient level of teachers in terms of methods of conducting distance learning, then after two months $36 \%$ of them were able to acquire the necessary competencies. Teachers had difficulty with student engagement and feared that they were "dishonest" during exams.

In a difficult situation, the report says, were those teachers who need special equipment for training. Subsequently, almost all universities sent methodological recommendations to teachers; in many universities, students themselves helped teachers switch to online. The authors of the report note that a certain part of teachers has negative attitudes towards online learning formats, which have practically not changed during their work at a distance. This is due to the increased labour intensity, as well as the unpreparedness of teachers to effectively use technology.

To improve the situation, it is necessary:

0 it is necessary to introduce massive retraining, which will be aimed not just at "passing the PC course";

- create a system of motivation for teachers who are actively involved in the use of digital resources;

- to form among teachers an idea not of a complete transition to online education, but of the introduction of elements of technology that will facilitate the work.

Already in March, it became clear that in every fifth university there are areas, for example, in the field of medicine, industry or creativity, courses in which cannot be completed in a distance format. Classes for such courses were either cancelled or postponed to the next academic year.

Distance education was implemented in one of two models: in most universities, teachers delivered lectures in the format of webinars and increased the interactivity of the process. In universities where there was no digital educational environment, the model was mainly used to send assignments and their subsequent verification via e-mail. Another quarter (28\%) of educational programs using online courses, including Coursera, Open Education.

The transition to distance learning led to the active introduction of proctoring technologies by universities, that is, technologies for monitoring the process of a student taking an exam remotely or defending an FQP. As the rectors note, it turned out that on the Russian market there is almost no competition among the providers of this service, and the existing ones are extremely expensive.

It is worth noting that proctoring causes to stress. Although this is a short-lived event, the period itself refers to high intellectual and emotional stress. This time consumes many psychic resources. The situation of taking exams remotely is indeed new for most students.

Even if we pass exams many times, our psyche still reacts strongly to stress. Moreover, the new format for conducting exams in such conditions is a completely unknown situation. This can cause anxiety, provoke thinking about negative 
scenarios for the development of events, and, in the worst case, negatively affect the success of the assignment.

Actions that can help solve the problem:

- part of the university program can be implemented in a full-time format outside the university;

- creation of a set of methods and rules for teaching online (digital didactics);

- In terms of digital infrastructure, distance learning has identified serious information security challenges. Ways must be found to provide security.

\section{Continuous distance education}

Continuous distance education is a broad concept that can be characterized as the absence of rest between the steps of education, for example, the absence of a gap between primary school and graduate school, or blurring the boundaries between personal time and study when a student devotes all his free time to his studies.

The system of lifelong education accompanies distance learning since the absence of personal contact with the teacher and the complete transition to online provides for the student's increased responsibility for their education (Andreev, 2005). However, in addition to the student psychological qualities, as self-control, discipline, the ability to independently motivate oneself to learn, special skills are also required.

Continuing education provides for the following skills on the part of the student (Petrov, 2013):

○ Conducting independent educational work;

- Independent search for all necessary information (both online and offline);

- Organization of personal information space and daily routine, time management;

- Participation in active training events, for example, surveys, projects, forums, discussions and others. This implies personal motivation for extracurricular and scientific activities;

- Appropriate technological equipment, and the ability to use audio and video communications, to work using modern technologies, the desire and ability to master new formats.

Among the main disadvantages of lifelong education, we single out the lack of free time to realize the value of training, the time spent, and the need for the acquired competencies.

Continuous distance education could shake a person's psyche if he was not ready for this, for example, during the coronavirus pandemic, when full-time students were forced to switch to a new education model. Here, in addition to the general difficult emotional background, the students found themselves hostage to circumstances under which they can only adjust. Lack of control over one's life and fear of uncertainty only amplify the possible negative effects of continuing education.

Lifelong learning is complementary to emotionally stable people who have made an independent choice to study with this educational model. It is not suitable for insufficiently motivated students, people who combine work with study, and those who cannot assimilate the information they receive without personal contact with the teacher. The forced transition to continuous distance education can lead to burnout, depression, apathy, loss of strength, sleep and eating disorders, decreased 
immunity, a tendency to make irrational decisions, inability to formulate their thoughts and defend their interests. In our opinion, continuous distance education is suitable for second higher education, postgraduate and graduate studies, while the student must choose the learning model himself: full-time, part-time, classical distance education or continuous distance education.

Every teacher and educational organization should draw a clear line between distance learning and continuing education, and not force students to participate in continuing education. A clear organization of the educational process, the necessary breaks between classes, homework, the completion of which does not exceed the number of academic hours in the subject, free time are the main aspects that contribute to the psychological well-being of students. If the educational process, which includes lectures, seminars, homework, written assessments and practice, takes up all the student's free time, then this is not distance education, but continuous distance learning, to which students have not given their consent.

In fact, the principle of lifelong education presupposes the classical system of a complete education in Russia (from preschool institutions to graduate school). The staged, gradual nature of education forces the population to participate in the psychologically difficult process of continuity, which interferes with the process of personality identification. It is believed that the discontinuity of education demotivates and postpones the transition to a new level of academic knowledge, but without the possibility of choice, it is likely that the student will be disappointed not only in his profession but also in education in general. Interruption of the training cycle is necessary for setting priorities, finding a personal "me", assessing their desires and career prospects. Lack of opportunity to think drives students into a cage and pressure from society and parent's forces students to make rash decisions. It should be emphasized that interrupting the education cycle is not a necessity, but merely an important option, an opportunity to choose or a pause to understand oneself. If the student nevertheless wants to participate in the system of continuing education, then higher education institutions should provide for possible fatigue and contribute to the development of the student's potential. In this regard, the highest levels of education, namely master's and postgraduate studies, should presuppose a studentcentered approach to learning, which is able to neutralize the negative effects of lifelong education.

\section{A student-centered approach to distance learning}

An educational process focused on the student, his characteristics, the need for freedom, and self-affirmation is the most psychologically favourable way to build learning. It is important to understand that the personal approach is understood as the teacher's attitude to the student as an equal, a person and a colleague.

The personality-oriented approach is focused on achieving maximum student progress, disclosing his own capabilities, realizing his potential, and creativity. This teaching system provides for the student's intrinsic motivation to learn, out of selfinterest, not fear of getting a bad mark or censure from society.

To implement this approach in distance learning is necessary to ensure equal conditions for studying the subject, develop a curriculum that promotes student selforganization, and develop a correct methodology for assessing this work (Salnikov, 
2010). For example, students themselves can choose a film that is related to the subject of study in order to talk about it in a practical lesson; or to give some students the opportunity to replace written work with oral. A student-centred approach to teaching provides for humanity, a system where the personalities of the teacher and the student are on an equal footing, have the same opportunities and weight in the discussion. In fact, this education system is the most complimentary to the trends of the 21 st century, in which a person requires identification, freedom, security for his development and realization of his potential.

Personality-oriented education is not the formation of a new personality according to given professional attitudes, but the creation of conditions for the development of its qualities, skills and abilities. This approach is based on the ethical-humanistic principle, that is, what is called "pedagogy of cooperation".

Yakimanskaya formulated the principles of student-centered education (Yakimanskaya, 2000):

$>$ Each student is unique;

$>$ The student is initially integral, and does not become a person in the learning process;

$>$ Education has as its goal the creation of favourable conditions for personal development;

$>$ The educational institution must be accompanied by the manifestation of the personality of each student.

In our opinion, the implementation of this approach provides:

○ appeal to individual knowledge, experience, interests of students;

- a variety of educational material in the form of its message;

- creating conditions for the development of the potential of the student;

- taking into account the congenital and acquired psychological characteristics of students (speech, fear of public speaking, and so on);

- consistency;

- creation of an appropriate educational environment;

$\circ$ retraining of teachers; every teacher must understand the goals and values of student-centered education.

It is logical that the student-centered approach to learning is mostly revealed when doing homework and seminars. Unfortunately, lecture practice is harder to adapt. The only possible options are a question-answer, variety in the presentation of information, special attention to students experiencing psychological and physical difficulties and give them the opportunity to choose a topic for the next lesson. The implementation of a student-centered approach is the main task of retraining teachers. The tension between discipline, academics, curriculum and contemporary challenges influences the formation of civil society.

\section{The heuristic strategy of distance education as a way out}

The heuristic strategy of distance education is a compromise between the traditional and student-centered learning system, which does not develop teamwork skills in the student, does not teach him how to practice objections.

In a broad sense, heuristics is the science that studies the processes of productive, creative thinking. In the last decade, it has come to be associated with an approach 
to learning rather than an independent field of knowledge, as many teachers practice its foundations to unleash the potential of the student.

Heuristic teaching strategy relies on a student-centered approach to learning. This strategy is based on personality, since the student himself formulates the value and content of the educational process, directly affects the assessment system and the result of all educational activities.

The heuristic strategy is based on the following principles (Khutorskoy, 1999):

$\circ$ humanity: each student requires an individual approach and attention so that education reveals his talents and potential, satisfies his goals and desires;

- possibility of free discussion: assumes variability of the answer, when a student develops the habit of expressing himself, learns to formulate thoughts, argue a position and understands that he has the right to disagree with the majority or with one, but a more authoritative person, for example, a teacher;

- meaning: practical orientation of theoretical knowledge. Each student should understand how the basics of biology, literate writing or knowledge of laws will be useful to him;

- reflection: the student should understand the value of his efforts, see an understandable relationship between learning, his dreams and goals and results, enjoy homework and the lessons themselves.

A heuristic strategy is the most comfortable psychological education model for distance learning. It not only creates a comfortable field for self-expression, as in the case of a personality-oriented approach, but also contributes to the development of teamwork skills, ways of conducting a discussion, and constructive discussion of problems.

Consider the technology of distance heuristic learning using the example of seminar work:

○ the teacher formulates an assignment or problem with an unknown solution, for example, prepare a presentation on a wide topic or an essay on any book from the bibliography;

o the student independently makes a decision and informs the teacher and/or his study group about his choice;

- after the preparation of the work, a collective discussion of personal results follows, a comparison of opinions, a rethinking of tasks. Here it is necessary to pose new problems, open questions, and expand the topic. The purpose of this process is to increase the student's interest in his own work so that later he can study the topic deeper and better assimilate the material.

Of course, when implementing a heuristic learning strategy, you can face a number of serious problems, such as:

o time management: in large groups of students, it is difficult to ensure that everyone has an equal opportunity to respond. One protracted performance can cut the performance of all the following participants;

- exceptional cases: some students experience resistance and increased responsibility when they are given such freedom of choice. It can increase anxiety, anxiety about the result, and sensitivity to comments; 
o the inability to implement the approach due to the specifics of the curriculum or the teacher's unwillingness to change the organization of the educational process.

Thus, we see a broad perspective in the heuristic learning strategy, which increases the student's involvement in the educational process, motivates him to learn new things, develops oratory skills and participates in the process of personal identification, since in the process of the in-depth study of the material, a sphere of scientific interests, is formed.

\section{Conclusion}

Like everything, distance learning has its pros and cons. Despite this, this challenge was able to prove that modern technologies made distance learning possible and no less workable than traditional. We see how this transition influenced all participants in the educational process. This experience should further help make education more effective with minimal harm to the psyche of people.

We can clearly see that a long-term pandemic has disrupted the usual order of learning for students and teachers. It influenced the mental and physical health of all participants in the educational process. However, the pandemic could help governments, educators and parents rethink education in the end. Schools in many countries have been practicing the traditional way of teaching for centuries, so we should not expect a quick switch to a new form of education.

Despite many negative aspects, the coronavirus may in the future give rise to the creation of a new, more effective teaching method.

\section{References}

Adams, T. \& Moore, M. (2007) High-risk health and credit behaviour among 18- to 25-year old college students. Journal of American College Health, 56, 101-108.

MacCabe, J. H., Lambe, M. P., Cnattingius, S., et al. (2010) Excellent school performance at age 16 and risk of adult bipolar disorder: a national cohort study. British Journal of Psychiatry, 196, 109-115.

Andreev A., (2005) Internet in the system of continuing education. Higher education in Russia, no. 7, pp. 91-94.

Petrov A., (2013) Distance learning technologies in the continuous education system. Open education, no. 5 , 2013, pp. 47-51

Salnikov V, (2010) Innovative learning: a person-centred approach. Higher education in Russia. №11. URL: https://cyberleninka.ru/article/n/innovatsionnoe-obuchenielichnostno-orientirovannyy-podhod

Yakimanskaya I.S. (2000) Person-Oriented Training at Modern School. - M: pp . 112

Khutorskoy A, (1999) Heuristic potential of distance learning. School technologies. - 1999.

- No5. - C. 236-247.

\section{Web references}

https://www.ncbi.nlm.nih.gov/pmc/articles/PMC5972137/

https://www.verywellhealth.com/is-working-at-my-computer-causing-my-headaches-

1719432

https://www.westernfrontonline.com/2020/06/08/online-classes-affect-students-sleep/ 
Geopolitical, Social Security and Freedom Journal, Volume 3 Issue 2, 2020

https://sphr.nihr.ac.uk/wp-content/uploads/2020/08/Young-Peoples-Mental-Healthduring-the-COVID-19-Pandemic-Report.pdf

https://www.rbc.ru/society/03/07/2020/5efdf6e09a794734267c9521

https://drive.google.com/file/d/1GMcBIoP8ITzE_WDVh4nFksX6lceotZY3/view 